\title{
With a little help from my goals: Integrating intergoal facilitation with the theory of planned behaviour to predict physical activity
}

Justin Presseau* ${ }^{1}$, Falko F. Sniehotta ${ }^{1}$, Jill J. Francis ${ }^{2}$ and Winifred A Gebhardt ${ }^{3}$

${ }^{1}$ School of Psychology, University of Aberdeen, Aberdeen, Scotland

${ }^{2}$ Health Services Research Unit, University of Aberdeen, Aberdeen, Scotland

${ }^{3}$ Clinical, Health and Neuropsychology, Leiden University, the Netherlands

Word count (exc. figures/tables): 5293

*Requests for reprints should be addressed to Justin Presseau, School of Psychology, William Guild Building, University of Aberdeen, Aberdeen AB24 3FX, Scotland (e-mail: j.presseau@abdn.ac.uk). 


\section{Acknowledgments}

This research was supported by a grant from the Improved Clinical Effectiveness through Behavioural Research Group (ICEBeRG) in Canada. We thank participants for their time in completing the measures, and the members of the Aberdeen Health Psychology group for their feedback. 


\begin{abstract}
\end{abstract}
Objective: Integration of a multiple goal theory approach into the theory of planned behaviour (TPB) to investigate how the perceived facilitating and conflicting relationships in multiple goal pursuit predict performance of a health-related behaviour. Design: Prospective design with 8-week follow-up.

Methods: At baseline, perceived intergoal facilitation and intergoal conflict were measured using personal projects analysis supplemented with standard TPB measures for physical activity. Self-reported physical activity was measured at follow-up eight weeks later. $\mathrm{N}=137$ participants completed measures at both time points (55.4\% response rate at follow-up).

Results: Hierarchical regression showed that perceived intergoal facilitation, but not intergoal conflict, directly predicted physical activity beyond intention and perceived behavioural control (PBC), accounting for more than four percent of additional variance in physical activity. Intergoal facilitation had an indirect effect on intention through attitude and PBC, and intention partially mediated the effect of intergoal facilitation on behaviour.

Conclusion: The perceived facilitating effect of pursuing other personal goals predicts the performance of a health-related behaviour over and above single behaviour-focused social cognitions.

Keywords: Personal projects, theory of planned behaviour, multiple goals, physical activity, intention, facilitation 


\section{With a little help from my goals: Integrating intergoal facilitation with the theory of planned behaviour to predict physical activity}

Everyday life is characterised by the pursuit of many goals; some normatively ordinary, some wildly idiosyncratic. Striving towards these goals involves performing multiple goal-directed behaviours (Carver \& Scheier, 1998). Goal-directed health behaviours, such as physical activity, are thus embedded within idiosyncratic systems of goal pursuit and cannot be fully understood in isolation (Austin \& Vancouver, 1996). However, predominant theoretical models used to study health behaviour, such as the theory of planned behaviour (TPB; Ajzen, 1991), isolate a health behaviour under investigation from the wider system of goal pursuit (Abraham \& Sheeran, 2003). Such ‘behavioural segregation’ assumes that either goaldirected behaviours are performed independently and without influencing one another, or that any such influence is mediated by cognitions and perceptions about the target behaviour (e.g. pursuing competing time-consuming goals may result in reduced perceived behavioural control for the target behaviour). This study aims to test whether these assumptions are supported by evidence or whether multiple goal pursuit has an independent effect in predicting a particular health-related behaviour such as physical activity.

Frequently used to predict physical activity, the TPB proposes that behaviour is a linear function of intention to perform the behaviour and perceived behavioural control (PBC) over performing the behaviour. Intention is in turn hypothesised to be a linear function of cognitions and perceptions (i.e., attitude, subjective norm, and PBC), each based on more specific beliefs (Ajzen, 1991). A review of 72 studies using the TPB (and its antecedent, the theory of reasoned action; Fishbein \& Ajzen, 1975) to predict physical activity-related behaviour revealed that the model accounted for $44 \%$ and $27 \%$ of the variance in intention and behaviour, respectively (Hagger, Chatzisarantis, \& Biddle, 2002). The predictive utility of the model has contributed to its wide application. However, several conceptual and empirical limitations have been identified (Ogden, 2003; Sniehotta, 2009b). For example, the 
assumption that the direct predictors, intention and PBC, are exhaustive in mediating all other influences on behaviours is not supported by evidence (Sniehotta, 2009a). Instead, there is good evidence for a growing number of additional independent predictors (Conner \& Armitage, 1998) and moderators (Cooke \& Sheeran, 2004). Though these additions challenge the parsimony of the model that is often seen as one of its main strengths, the utility of additional predictors has particular relevance in applied research by providing potential new targets upon which to map intervention techniques to change behaviour (Michie, Johnston, Francis, Hardeman, \& Eccles, 2008). These tests of theory augmentation provide important advances, though few address the issue of behavioural segregation. Rhodes and Blanchard (2008) provide an exception to this by investigating sedentary behaviours alongside physical activity using the TPB. They found that intention to watch television predicted additional variance in physical activity (PA) behaviour beyond PA-specific intention and PBC. However, sedentary behaviours are but one of many potential activities individuals pursue. Because individuals strive for many different personally-salient goals at a time, the focus of the present study was on assessing how these other personal goals as a goal system may influence participating in physical activity.

\section{Assessing multiple personal goals}

Several Personal Action Constructs (PACs) have been introduced to encompass the idiosyncratic features and inter-related nature of the goals which form individuals' personal goal systems (Cantor, 1990). These PACs include concepts such as personal projects (Little, 1983), personal strivings (Emmons, 1986), current concerns (Klinger, 1977), and life tasks (Cantor, Norem, Niedenthal, Langston, \& Brower, 1987). Personal projects were selected for this study to represent the range of personal goals characterising the objectives that an individual is currently pursuing in the context of their life (Little, 1996). Defined as "extended sets of personally salient action in context" (Little, 2007, p.25), personal projects 
can be studied using a standard elicitation and rating methodology known as personal projects analysis (PPA; Little \& Gee, 2007). PPA and similar methodologies have been used to investigate how features of individuals' personal goal systems relate to health behaviours. Women who exercised to achieve higher-order 'weight loss' or 'health benefit' goals reported less physical activity than those who exercised for higher-order and more 'well-being' and 'stress reduction' goals (Segar, Eccles, \& Richardson, 2008). There is also some evidence suggesting a predictive association between features of individuals' goal system and health behaviour. Perceptions of social support and meaningfulness of individuals' most important personal goal negatively predicted alcohol consumption beyond social and affect-enhancing 'motives' (i.e. outcome expectations), respectively (Lecci, MacLean, \& Croteau, 2002). Furthermore, perceptions of how different personal goals affect each others' pursuit has been found to predict physical activity (Riediger \& Freund, 2004), and marijuana initiation and use (Simons \& Carey, 2003). Together, these results suggest that the influence of the wider system of personal goal pursuit on performance of a particular health-related behaviour should be considered. However, to our knowledge, no study has yet investigated whether the perceived influence of a personal goal system predicts the performance of a health-related behaviour beyond a specific social cognition model such as the TPB.

\section{Intergoal conflict, intergoal facilitation and physical activity}

Pursuit of a particular goal implies resource (e.g. time, energy, money) consumption that may leave fewer resources available for the remainder of the goals the individual may be actively pursuing (Kruglanski et al., 2002). Depending upon the structure and content of an individual's goal system, this between-goal competition can potentially lead to goal pursuits influencing one another in two independent ways: 1) facilitating, whereby pursuit of Goal X helpfully leads to or is associated with pursuit of Goal Y; and/or 2) conflicting, whereby pursuit of Goal X impedes or interferes with pursuit of Goal Y (Riediger \& Freund, 2004). 
Intergoal facilitation should be distinguished from Triandis' facilitating conditions construct (Triandis, 1980). While the latter explicitly reflects external environmental and situational factors that influence performance of a behaviour, intergoal facilitation is specifically to do with the extent to which pursuing one goal is perceived to helpfully influence the pursuit of another goal.

Traditionally, conflict and facilitation have been measured as two opposing poles along the same bipolar continuum. However, Riediger and Freund (2004) provide evidence suggesting that intergoal conflict and intergoal facilitation are better conceptualised as two separate constructs and compellingly argue for their independent measurement.

Previous studies investigating the effect of intergoal conflict and facilitation on behaviour have mainly done so without considering existing social cognition models such as the TPB. Cross-sectional research has shown that non-exercisers reported exercising as interfering with pursuing a number of their other personal goals (Gebhardt \& Maes, 1998). Extending these findings, Karoly and colleagues (2005) investigated self-regulatory cognitions (e.g. self-monitoring, planning, social comparison) related to an exercise goal and a personal goal most interfering with it. Comparing regular to irregular exercisers, the latter showed significantly higher self-regulatory cognitions towards the conflicting goal, whereas regular exercisers showed no such difference between the exercise goal and the goal most interfering with it. In a longitudinal study, Riediger and Freund (2004) showed that intergoal facilitation but not intergoal conflict predicted objective gym attendance four and five months after baseline (but not at 1, 2, or 3 months). Within a number of control analyses, Riediger (2001) separately controlled for self-efficacy or for how concrete participants ideas about their future activities were and found that the joint addition of intergoal facilitation and conflict significantly added to the prediction of exercise behaviour averaged over 5 months. It remains unclear whether effects would remain robust when simultaneously controlling for 
standard measures of both, intention and perceived behavioural control, and whether these effects only play a role in long-term (>3 months) goal pursuit.

\section{The present study}

This study aimed to integrate the TPB and components of goal theory to enhance the prediction of health behaviour. We used TPB constructs as a theoretical foundation and investigated whether perceived intergoal relationships enhanced the prediction of the two main outcomes in the TPB; intention and behaviour. Evidence and theory led us to propose three competing hypotheses, which we evaluated against one another:

\section{Hypothesis 1: Independent prediction of behaviour beyond the TPB}

Results from the literature demonstrate a predictive effect of intergoal facilitation and intergoal conflict on health behaviour. We therefore hypothesised that the perceived facilitating and conflicting effect of pursuing other personal goals would directly predict health behaviour when simultaneously controlling for intention and PBC from the TPB.

Hypothesis 2: Interaction between intention and multiple goal pursuit constructs It may be that individuals with strong intention to perform a health-related behaviour do so more or less frequently depending on the helpful or hindering effect of pursuing other concomitant projects. Given the literature suggesting that strong intention does not always lead to behavioural performance (Orbell \& Sheeran, 1998), we hypothesised that individuals with high intention would show significantly higher performance when their other personal goals are perceived to highly facilitate or have low conflict with the focal PA behaviour.

Hypothesis 3: Effect of multiple goal pursuit constructs mediated by the TPB Ajzen and Manstead (2007) suggest that the TPB's constructs should mediate all other 'background' variables' (e.g. environmental, personal, and demographic) effects on intention and behaviour. The perceived influence of other goal pursuits could arguably be considered among these background variables. Pursuit of other projects may influence an individuals' 
intention to perform a particular health-related behaviour by affecting their attitude, subjective norm, and/or perceived control over performing that health-related behaviour. We therefore hypothesised that perceived intergoal facilitation and conflict would influence intention, and be mediated the predictors of intention in the TPB.

\section{Method}

\section{Participants}

At Time 1 during regular term time, a sample of 260 undergraduate students (mean age = 21.05 years; $s d=6.28 ; 201$ [77.3\%] women, 58 [22.3\%] men) in the north-east of Scotland completed baseline measures. At Time 2, two months later, 144 participants completed follow-up measures (response rate $=55.4 \%$ ). The final sample comprised 137 participants $(7$ participants were excluded due to not fully completing the Time 1 procedure). Drop out analyses found no significant differences in terms of age, gender, intention, attitude, subjective norm, PBC, intergoal facilitation, or intergoal conflict (all ps >.08).

\section{Measures and procedure - Time 1}

The measures integrated standard TPB items into a tailored personal project analysis (PPA) framework, and were administered at Time 1 to consenting participants using a modified Microsoft Excel-based procedure originally developed by Little (2006). Participants were asked to list up to 11 personal projects which they would actively pursue (on more than one occasion) during the subsequent 3 months. Personal projects were defined as "things you choose to do or things you have to do; they may be things you are working towards or things you are trying to avoid. Personal Projects may be related to any aspect of your daily life: university, work, home, leisure and community, among others" (c.f. Little, 2006). Given the longitudinal follow-up, we instructed participants to focus on projects they would be actively engaged in over the next 3 months. To avoid 'artificial' projects, respondents were allowed to enter fewer than the total possible number of projects (Wallenius, 2000). Subsequent to 
project elicitation (and in a departure from traditional PPA), two projects were added to participants' lists such that each person would have two projects common between them: 'participate in regular physical activity' and 'regularly study before/after class for my uni courses'. Given that 'participate in regular physical activity' was added to everyone's list, it was deliberately kept at a general level in order to represent whatever constituted regular physical activity for each participant. Participants were then asked to refine their list to at most eight projects that they felt were the most important to describing their lives, while also taking care to exclude any of their projects that were identical or nearly identical to either of the two added projects.

Following elicitation and refinement of projects, participants completed a TPB questionnaire on participating in regular physical activity, using direct measures with wording based on Armitage (2005) ${ }^{1}$. Intention to participate in regular physical activity was measured with three items (Cronbach's $\alpha=.75$ ): e.g. "how often do you intend to participate in regular physical activity?" (1-Never to 7-Frequently). PBC was measured with four items (Cronbach's $\alpha=.91$ ): e.g. "I am confident that I can participate in physical activity on a regular basis" (1-Disagree to 7-Agree). Attitude was measured on semantic differential scales using the common stem "for me, participating in regular physical activity would be..." followed by six different items, all scaled from 1 to 7 (Cronbach's $\alpha=.86$ ): (BoringStimulating); (Bad-Good); (Unhealthy-Healthy); (Dull-Interesting); (Unpleasant-Pleasant); (Useless-Useful). Finally, Subjective Norm was assessed using three items (Cronbach's $\alpha=$ .73): e.g. "people who are important to me would..." (1-Disapprove of my participation in regular physical activity to 7-Approve of my participation in regular physical activity).

\footnotetext{
${ }^{1}$ Note: The wording used was identical to Armitage (2005) except for the following changes: Armitage (2005) used two intention items, whereas we added an additional intention item: "I do not intend to participate in regular physical activity" (reverse scored). Furthermore, we described all intention items in terms of "participate in regular physical activity'. For PBC, we replaced "How much personal control do you feel you have over participating in regular physical activity?" (Armitage, 2005, p.237) with the example provided in the measures and procedure section.
} 
Participants then rated their personal projects on a series of standard PPA dimensions (e.g. importance, difficulty - not reported here), including measures of intergoal facilitation and conflict. In standard PPA, the latter two are typically assessed together using a project cross-impact matrix (Little, 1983) wherein participants iteratively rate the extent that each project conflicts with and facilitates each other project. We sought to maintain standard PPA modules as much as possible while also limiting the burden on time for participants and to simplify the distinction between the intergoal constructs for participants. Intergoal facilitation and conflict were therefore measured independently using similar measurement techniques. Participants rated the degree that their other projects facilitated their participating in regular physical using a metric from 0 to 10 to rate "To what extent does each project help/facilitate your participation in regular physical activity? (Use 10 if a project helps/facilitates you to participate in regular physical activity, and 0 if this project does not help/facilitate you at all to participate in regular physical activity)" for each personal project. A facilitation score was then computed, composed of the mean of these facilitation ratings. The project cross-impact matrix was modified to focus solely on intergoal conflict. A 10x10 matrix was composed of participants' personal projects along both the rows and columns of the matrix (Presseau, Sniehotta, Francis, \& Little, 2008). Completion of the matrix proceeded in a pairwise manner where each project was compared iteratively to each other project and a rating of 0 ('does not conflict at all') to 10 ('conflicts a lot') was given to reflect "to what extent does actively engaging in each of these projects...” (e.g. 'Finding a part-time job') “...conflict with engaging in each of these projects" (e.g. 'Going out with my friends'). The mean rating of the perceived conflict that pursuing each of participants' personal projects had with pursuing the PA project was used as the indicator of intergoal conflict.

Finally, participants were asked to categorise their projects into one of seven categories most appropriate to describing each project, in line with standard PPA (i.e. 
Academic, Occupational, Health/Body, Interpersonal, Intrapersonal, Leisure, and Maintenance).

\section{Measures and procedure - Time 2}

At follow-up 8 weeks later, consenting participants were emailed a link to a short web-based questionnaire which measured self-reported frequency of physical activity. Frequency of participation in physical activity was measured using a single item scaled from ' 0 times' to '10+ times' asking "how often have you participated in physical activity for at least 30 minutes per session during your free time in the last week?” based on a validated measure used by Gionet and Godin (1989). An eight week span was selected for follow-up to maximise the potential that projects were being actively pursued and therefore might influence participating in regular physical activity.

\section{Results}

\section{Descriptive statistics and correlations}

Participants listed a mean of 9.08 projects $(s d=1.49)$ during the elicitation phase, and refined their list to a mean of 7.12 projects ( $(\mathrm{sd}=1.10)$. Besides the two personal projects added by the researchers, participants rated a total of 941 projects of which $17.3 \%$ were selfcategorised as academic projects (e.g., "attend lectures regularly”), 7.0\% occupational (e.g., “work every Friday and Saturday night”), 12.2\% health/body (e.g., "lose a further 7lbs”), 20\% interpersonal (e.g., "spend time with Tim”), 11.4\% intrapersonal (e.g., "volunteer more with charities"), 19.6\% leisure (e.g., "sightseeing"), and 12.5\% maintenance-related (e.g., "become more organised") projects. Descriptive statistics and correlations between social cognition scores, intergoal constructs and Time 2 self-reported behaviour are presented in Table 1 . The median reported frequency of physical activity was 3 times in the past week, with $57 \%$ of the sample reporting being physically active at least 3 times. Participants reported relatively strong intention, PBC, subjective norm and positive attitude towards 
participating in regular physical activity. Attitude, subjective norm, and PBC were mediumto-strongly (Cohen, 1992) correlated with intention, in accordance with the assumptions of

the TPB. In line with previous research (Riediger \& Freund, 2004), intergoal facilitation and intergoal conflict were not correlated with each other. While intergoal facilitation was significantly correlated with Time 2 behaviour and all TPB constructs, intergoal conflict was correlated with only attitude and subjective norm scores. The weight of evidence supporting intention and PBC as predictors of behaviour argued in favour of controlling for their effect before testing the predictive utility of intergoal constructs. However, given the lack of correlation of intergoal conflict with the main outcomes of interest in the TPB (i.e. intention and behaviour) subsequent analyses involving intergoal conflict focused only upon testing the interaction with intention hypothesis.

\section{$<$ TABLE 1>}

\section{Direct and moderated effects on behaviour}

A three-step hierarchical regression tested whether intergoal facilitation independently predicted PA behaviour beyond the TPB constructs, and whether it moderated the intentionbehaviour relationship. All predictors were mean-centred prior to analysis (Aiken \& West, 1991). At Step 1, the proximal predictors of the TPB (intention and PBC) were entered and accounted for $16.6 \%$ of the variance in Time 2 self-reported PA. Step 2 tested for a main effect of intergoal facilitation on behaviour, controlling for the effect of intention and PBC, and found that an additional $4.3 \%(p<.01)$ of the variance in behaviour was explained. Step 3 tested the hypothesis that intergoal facilitation moderated the intention behaviour relationship by adding the product term of mean centred intention and intergoal facilitation to the model. No significant interaction was found (two-tailed $p=.08$ ). Hierarchical regression results testing the effect of intergoal facilitation in predicting Time 2 behaviour are presented in Table 2. A similar hierarchical regression testing whether intergoal conflict moderated the 
intention-behaviour relationship did not find support for an interaction effect $\left(\Delta R^{2}=.006\right.$, $p=.32)$.

\section{$<$ TABLE 2>}

\section{Mediated effect of intergoal facilitation on intention and behaviour}

To test whether the TPB mediated the perceived facilitating effect of other projects on PA behaviour, we tested two bootstrapped mediation models (Preacher \& Hayes, 2008). Bootstrapped methods were preferred for their higher statistical power over the Baron and Kenny method and more appropriate distributional assumptions than the Sobel test (MacKinnon, Fairchild, \& Fritz, 2007; Preacher \& Hayes, 2008).

The first model tested whether intergoal facilitation indirectly predicted intention through the determinants of intention as proposed by the TPB (attitude, subjective norm and PBC). Facilitation had a significant specific indirect effect on intention through attitude $\left(B=.10\right.$, BCa $95 \% \mathrm{CI}^{2}=.05$ to .20$)$ and $\mathrm{PBC}(B=.04$, BCa $95 \% \mathrm{CI}=.002$ to .11$)$ but not subjective norm $(B=.01$, BCa $95 \% \mathrm{CI}-.003$ to .04$)$. A pairwise contrast between the indirect effect through attitude and PBC was tested to assess whether their effects were distinguishable (Preacher \& Hayes, 2008). They did not differ (BCa 95\% CI = -.03 to .19). While the total effect (i.e. before accounting for the mediators) of facilitation on intention was significant $(B=.12, \mathrm{p}<.05)$, the direct effect (i.e. accounting for the indirect effect of facilitation on intention through attitude and PBC) was not significant. This suggests a full mediation (see Figure 1).

The second bootstrapped mediation model tested whether any observed mediation of effects in predicting intention continued on to predict behaviour. Intention was thus tested as mediator of the predictive effect of intergoal facilitation on Time 2 behaviour. A significant indirect effect of intergoal facilitation on Time 2 behaviour was observed $(B=.08,95 \% C I=$

\footnotetext{
${ }^{2}$ BCa 95\%CI= Bias Corrected and Accelerated 95\% Confidence Interval
} 
.01 to .17). The total effect of intergoal facilitation on behaviour (without accounting for the mediator) was significant $(B=.37, \mathrm{p}<.01)$. Accounting for the indirect effect through intention attenuated the total effect on behaviour, but not completely $[B=.29, \mathrm{p}<.01])$, suggesting a partial mediation.

$<$ FIGURE 1 $>$

\section{Discussion}

\section{Prediction of physical activity from perceived intergoal facilitation}

The evidence from these analyses supports a significant independent effect of perceived intergoal facilitation on frequency of reported PA beyond TPB constructs. This main effect replicates and extends Riediger and Freund's (2004) and Riediger's (2001) findings by simultaneously controlling for both proximal predictors (intention and PBC) in the theory of planned behaviour using a different context and different methods. Furthermore, this study significantly predicted PA at 2 months follow-up. Compared to Riediger and Freund's (2004) report of observing the effect at four and five months after baseline, but not at follow-up months one, two or three, the current study suggests that intergoal facilitation predicts behaviour on a shorter interval as well. The timing of this effect may largely depend on whether the facilitating personal goals have been performed prior to follow-up assessment. By constraining the timeframe of projects to 'projects actively pursued in the next 3 months' this study minimised the potential for long-term projects being listed which participants may not be actively pursuing at Time 2 .

The significant main effect of intergoal facilitation beyond behaviour-specific intention and PBC is compelling, as it was equivalent to the magnitude, yet independent, of intention. Furthermore, the size of the effect was equivalent to the additional amount of variance that PBC explains in behaviour beyond intention in exercise-related TPB studies (Hagger et al., 2002). The facilitating effect is based on ratings from participants' own 
personal projects rather than solely researcher-provided projects thereby considering the health behaviour of research interest as embedded within the participant's own goal system. These results support the use of these meaningful idiographic assessments of individuals' own personal projects and their perceived effect on performing a health behaviour, which can be tested nomothetically using between-subjects analyses. The indirect effect of intergoal facilitation on intention via attitude and PBC (albeit based on Time 1 data only) also supports the idea of a motivational role for intergoal facilitation. These findings suggest that intention to participate in regular physical activity may be informed by attitudes and perceptions of control that take into account the perceived facilitative effect of other personal projects. This supports the assumption that the TPB constructs mediate the effect of wider contextual factors such as pursuing other projects. However, the more proximal mediation model suggests that the TPB only partially mediates the effect of intergoal facilitation to Time 2 behaviour.

While the interaction terms did not statistically add to the regression equation, such interactions are recognised as being difficult to detect in predictive studies, are often underestimated, and when detected are typically of the order of magnitude observed in this study (McClelland \& Judd, 1993). While it is premature to draw conclusions from the nonsignificant interaction between intention and perceived intergoal facilitation, implications of the non-significant trend observed argue in favour of replication in a study powered to detect smaller effects.

Taken together, the findings in this study suggest that the perceived facilitative projects may influence both intention to perform a health-related behaviour and its subsequent performance directly and indirectly. This observed dual role may actually depend on the nature of the personal projects that compose the investigated goal system; particular subsets of projects may relate to intention and/or behaviour more than others. The composite 
measure of intergoal facilitation includes a variety of idiosyncratically defined projects. The perceived facilitating effect of some of these projects may directly account for additional variance in reported physical activity, while others may predict cognitions and motivation to do so. This implies that different aspects of the goal system may differentially affect motivation and behaviour. Constraining the project elicitation phase to a context in which particular types of projects are likely to be pursued may provide a way to test whether perceived intergoal facilitation's effect on intention and/or behaviour is moderated by type of project.

While the effect of perceived intergoal facilitation on intention was mediated by direct measures of TPB variables, an unanswered question remains regarding how intergoal perceptions relate to behavioural, normative and control beliefs in the TPB. Conceptualised as resource-related perceptions, intergoal conflict and facilitation have similarities with control beliefs. However, rather than reflecting the resources (or lack thereof) to perform a behaviour as do control beliefs (Ajzen, 1991), intergoal facilitation and conflict are perceptions of how other personal goals influence resource availability. Perceived facilitating or conflicting personal goals may also influence behavioural and normative beliefs about PA. Standard belief elicitation studies are unlikely to capture perceived influences of multiple goal pursuit; indeed, assessing perceived intergoal relations has been shown to substantially supplement belief elicitations (Presseau, Sniehotta, Francis, \& Campbell, 2009). Nevertheless, the association between intergoal facilitation, conflict, and belief-based measures in the TPB remains an empirical question that merits further investigation.

A theoretical implication of this study's findings is that while intention remains a strong determinant of future behaviour, the system of other personal goals pursued also has a direct and indirect facilitative influence on enactment. This finding provides additional 
empirical support for theoretical propositions in the literature for extending the social cognition models of behaviour such as the TPB to include perceptions about other goaldirected behaviours performed by the individual (Abraham \& Sheeran, 2003). In this sample, the extent of facilitative interconnectedness of individuals' goal systems was salient enough to participants to explain additional variance in their physical activity cognitions and behaviours. The broader implication of this study is that investigating health behaviours as embedded within a system of multiple goal pursuit is a useful way of advancing singlebehaviour focused models such as the TPB. Asking individuals to list their multiple goals and rate how they perceive them to influence one another may be a novel experience for participants, and a potentially useful one from an intervention perspective. Simple increased salience of the facilitative relations between people's projects may promote the performance and persistence of a health-related behaviour by allowing participants to assess how it would integrate into their existing goal system (Presseau et al., 2008). This could be supplemented by proactive planning to promote the alignment of these facilitative relations and shield against threats to their pursuit (Darker, French, Eves, \& Sniehotta, in press; Sniehotta, Scholz, \& Schwarzer, 2006).

\section{The lack of predictive utility of perceived intergoal conflict}

The lack of correlation between intergoal facilitation and intergoal conflict supports their discriminative construct validity. Despite the intuitive appeal of intergoal conflict being associated with lower physical activity levels, no such effect was found in this study, in line with results from Riediger and Freund (2004). Although non-significant findings should be interpreted with great caution, it is possible this may be seen as an indication that individuals in this study effectively self-regulate the perceived conflict between projects to minimise their impact on their intention and actual physical activity. This is consistent with the evidence suggesting an association between intergoal conflict and low well-being (Pomaki, 
Maes, \& ter Doest, 2004; Riediger \& Freund, 2004). In other words, healthy and relatively active individuals may use a number of self-regulatory strategies to minimise any persistent intergoal conflict in order to avoid the detriments to their subjective well-being. Thus, physical activity may be well-integrated into their wider system of goal pursuit, particularly given that $57 \%$ of the sample reported being physically active at least 3 times in the past week. This is consistent with Karoly et al.'s (2005) findings suggesting that regular exercisers do not distinguish between self-regulatory strategies used to pursue their self-identified most conflicting personal goal and those used for their exercise goal. This may also help to explain the lack of predictive utility of intergoal conflict on exercise behaviour in Riediger and Freund's (2004) sample of highly motivated individuals joining an exercise gym. Intergoal conflict may be of higher relevance for physical activity health behaviours in more sedentary populations (Gebhardt \& Maes, 1998) or on those with lower self-regulatory skills. The lack of association may also be due to the $10 \times 10$ project cross-impact matrix used to assess intergoal conflict which was more complicated to complete than was the intergoal facilitation measure. Nevertheless, the direction of association of other constructs with intergoal conflict in the correlation matrix was negative, as expected. Furthermore, the results corroborate the lack of effect of intergoal conflict reported by Riediger and Freund (2004) despite use of different measures. Future research should assess whether a simplified assessment of intergoal conflict improves prediction.

\section{Limitations and future research}

This study is limited by a reasonably physically active student sample whose views may not be generalisable to less active samples, by the self-reported nature of the outcome variable, and the correlational design that limits causal conclusions. However, the novel integrative theoretical principles under study justified the design choices. While the observed independent predictive effect of perceived intergoal facilitation was modest, it nevertheless 
supports and extends existing evidence in the literature supporting this effect. Selecting physical activity as the focal behaviour provides consistency with the literature, however further research is needed to corroborate the observed effects in other behavioural contexts. While bootstrapped models provided evidence of "internal replicability" (Thompson, 1994, p.171) of the mediated effects, future research should use experimental methods and, ideally, different and objectively measured health behaviours besides physical activity to corroborate the findings.

Aggregation of individual ratings of conflict and facilitation to form a nomothetic score may undermine the individual effect of a particular project, thereby resulting in a lower overall effect. Nevertheless, such a perspective provides an indication of the perceived facilitative and conflicting effect of the goal system, which may hold greater ecological validity. Weighting of projects in terms of other factors such as relative importance may reconcile this measurement issue in future research.

More generally, the specificity and type of projects generated by participants varied considerably between individuals. Future research should investigate the extent to which these factors moderate the relationships tested in this study.

A 2-month follow-up was selected to maximise the potential that projects were being pursued; however some projects listed may not have been pursued until after the follow-up, and thus would not have influenced exercising. Nevertheless, the reverse may also be true: had a follow-up of 3 months or more been selected, projects may have been altered, achieved or put on hold by the time the follow-up assessment was made. Future research should investigate whether these effects are dependent on the timeline of pursuit of projects when the focal behaviour is measured.

To ensure continuity with measures used by Armitage (2005), we did not specify a timeline for the TPB items. This, along with the relatively long follow-up period, may have 
contributed to a lower level of variance explained in behaviour. It remains to be seen whether the observed effect of intergoal facilitation is maintained with the addition of a time specification when assessing TPB constructs.

\section{Conclusions}

This study provides evidence that perceiving a facilitating effect of other personal projects predicts intention to perform and performance of a health-related behaviour beyond the single-behaviour cognitive predictors in the TPB. Integrating this feature of multiple goal pursuit into social cognition models may help to contextualise a single health-related behaviour within individuals' wider system of multiple goal pursuit. 


\section{References}

Abraham, C., \& Sheeran, P. (2003). Implications of goal theories for the theories of reasoned action and planned behaviour. Current Psychology: Developmental, Learning, Personality, Social, 22, 264-280.

Aiken, L. S., \& West, S. G. (1991). Multiple regression: Testing and interpreting interactions. Thousand Oaks, CA: Sage Publications.

Ajzen, I. (1991). The theory of planned behavior. Organizational Behavior and Human Decision Processes, 50, 179-211.

Ajzen, I., \& Manstead, A. S. R. (2007). Changing health-related behaviors: An approach based on the theory of planned behavior. In K. van den Bos, M. Hewstone, J. de Wit, H. Schut \& M. Stroebe (Eds.), The scope of social psychology: Theory and applications (pp. 43-63). New York: Psychology Press.

Armitage, C. J. (2005). Can the theory of planned behavior predict the maintenance of physical activity? Health Psychology, 24, 235-245.

Austin, J. T., \& Vancouver, J. B. (1996). Goal constructs in psychology: Structure, process, and content. Psychological Bulletin, 120, 338-375.

Cantor, N. (1990). From thought to behavior: "having" and "doing" in the study of personality and cognition. American Psychologist, 45, 735-750.

Cantor, N., Norem, J. K., Niedenthal, P. M., Langston, C. A., \& Brower, A. M. (1987). Life tasks, self-concept ideals, and cognitive strategies in a life transition. Journal of Personality and Social Psychology, 53, 1178-1191. 
Carver, C. S., \& Scheier, M. F. (1998). On the self-regulation of behavior. New York, NY, US: Cambridge University Press.

Cohen, J. (1992). A power primer. Psychological Bulletin, 112, 155-159.

Conner, M., \& Armitage, C. J. (1998). Extending the theory of planned behavior: A review and avenues for further research. Journal of Applied Social Psychology, 28, 1429-1464.

Cooke, R., \& Sheeran, P. (2004). Moderation of cognition-intention and cognition-behaviour relations: A meta-analysis of properties of variables from the theory of planned behaviour. British Journal of Social Psychology, 43, 159-186.

Darker, C. D., French, D. P., Eves, F. F., \& Sniehotta, F. F. (in press). An intervention to promote walking amongst the general population based on an extended theory of planned behaviour: A waiting list randomised controlled trial. Psychology and Health,

Emmons, R. A. (1986). Personal strivings: An approach to personality and subjective wellbeing. Journal of Personality and Social Psychology, 51, 1058-1068.

Fishbein, M., \& Ajzen, I. (1975). Belief, attitude, intention, and behavior: An introduction to theory and research. Reading, MA: Addison Wesley.

Gebhardt, W. A., \& Maes, S. (1998). Competing personal goals and exercise behaviour. Perceptual and Motor Skills, 86, 755-759.

Gionet, N. J., \& Godin, G. (1989). Self-reported exercise behaviour of employees: A validity study. Journal of Occupational Medicine, 31, 969-973.

Hagger, M. S., Chatzisarantis, N. L. D., \& Biddle, S. J. H. (2002). A meta-analytic review of the theories of reasoned action and planned behavior in physical activity: Predictive 
validity and the contribution of additional variables. Journal of Sport \& Exercise Psychology, 24, 3-32.

Karoly, P., Ruehlman, L. S., Okun, M. A., Lutz, R. S., Newton, C., \& Fairholme, C. (2005). Perceived self-regulation of exercise goals and interfering goals among regular and irregular exercisers: A life space analysis. Psychology of Sport and Exercise, 6, 427-442.

Klinger, E. (1977). Meaning \& void: Inner experience and the incentives in people's lives. Minneapolis: University of Minnesota Press.

Kruglanski, A. W., Shah, J. Y., Fishbach, A., Friedman, R., Chun, W. Y., \& Sleeth-Keppler, D. (2002). A theory of goal systems. In M. P. Zanna (Ed.), Advances in experimental social psychology (pp. 331-378). San Diego: Academic Press.

Lecci, L., MacLean, M. G., \& Croteau, N. (2002). Personal goals as predictors of college students drinking motives, alcohol use and related problems. Journal of Studies on Alcohol, 63, 620-630.

Little, B. R. (1983). Personal projects: A rationale and method for investigation. Environment and Behavior, 15, 273-309.

Little, B. R. (1996). Free traits, personal projects and idio-tapes: Three tiers for personality psychology. Psychological Inquiry, 7, 340-344.

Little, B. R. (2006). Interactive PPA workbook beta [Microsoft Excel file]. Retrieved September 15, 2007, from http://www.brianrlittle.com/ppa/index.htm 
Little, B. R. (2007). Prompt and circumstance: Generative contexts of personal projects analysis. In B. R. Little, K. Salmela-Aro \& S. D. Phillips (Eds.), Personal project pursuit: Goals, action, and human flourishing (pp. 3-49). London: Lawrence Erlbaum.

Little, B. R., \& Gee, T. L. (2007). The methodology of personal projects analysis: Four modules and a funnel. In B. R. Little, K. Salmela-Aro \& S. D. Phillips (Eds.), Personal project pursuit: Goals, action, and human flourishing (pp. 51-93). London: Lawrence Erlbaum.

MacKinnon, D. P., Fairchild, A. J., \& Fritz, M. S. (2007). Mediation analysis. Annual Review of Psychology, 58, 593-614.

McClelland, G. H., \& Judd, C. M. (1993). Statistical difficulties of detecting interactions and moderator effects. Psychological Bulletin, 114, 376-390.

Michie, S., Johnston, M., Francis, J. J., Hardeman, W., \& Eccles, M. P. (2008). From theory to intervention: Mapping theoretically derived behavioural determinants to behaviour change techniques. Applied Psychology: An International Review, 57, 660-680.

Ogden, J. (2003). Some problems with social cognition models: A pragmatic and conceptual analysis. Health Psychology, 22, 424-428.

Orbell, S., \& Sheeran, P. (1998). "Inclined abstainers": A problem for predicting healthrelated behaviour. British Journal of Social Psychology, 37, 151-165.

Pomaki, G., Maes, S., \& ter Doest, L. (2004). Work conditions and employees' self-set goals: Goal processes enhance prediction of psychological distress and well-being. Personality and Social Psychology Bulletin, 30, 685-694. 
Preacher, K. J., \& Hayes, A. F. (2008). Asymptotic and resampling strategies for assessing and comparing indirect effects in multiple mediator models. Behavior Research Methods, 40, 879-891.

Presseau, J., Sniehotta, F. F., Francis, J. J., \& Campbell, N. C. (2009). Multiple goals and time constraints: Perceived impact on physicians' performance of evidence-based behaviours. Implementation Science, 4, 77.

Presseau, J., Sniehotta, F. F., Francis, J. J., \& Little, B. R. (2008). Personal projects analysis: Opportunities and implications for multiple goal assessment, theoretical integration, and behaviour change. European Health Psychologist, 10, 32-36.

Rhodes, R. E., \& Blanchard, C. M. (2008). Do sedentary motives adversely affect physical activity? Adding cross-behavioural cognitions to the theory of planned behaviour. Psychology \& Health, 23, 789-805.

Riediger, M. (2001). On the dynamic relations among multiple goals: Intergoal conflict and intergoal facilitation in younger and older adulthood. Unpublished doctoral dissertation, Freie Universitat Berlin,

Riediger, M., \& Freund, A. M. (2004). Interference and facilitation among personal goals: Differential associations with subjective well-being and persistent goal pursuit. Personality and Social Psychology Bulletin, 30, 1511-1523.

Segar, M. L., Eccles, J. S., \& Richardson, C. R. (2008). Type of physical activity goal influences participation in healthy midlife women. Women's Health Issues, 18, 281-291.

Simons, J. S., \& Carey, K. B. (2003). Personal strivings and marijuana use initiation, frequency, and problems. Addictive Behaviours, 28, 1311-1322. 
Sniehotta, F. F. (2009a). An experimental test of the theory of planned behaviour. Applied Psychology: Health and Well-being, 1, 257-270.

Sniehotta, F. F. (2009b). Towards a theory of intentional behaviour change: Plans, planning and self-regulation. British Journal of Health Psychology, 14, 261-273.

Sniehotta, F. F., Scholz, U., \& Schwarzer, R. (2006). Action plans and coping plans for physical exercise: A longitudinal intervention study in cardiac rehabilitation. British Journal of Health Psychology, 11, 23-37.

Thompson, B. (1994). The pivotal role of replication in psychological research: Empirically evaluating the replicability of sample results. Journal of Personality, 62, 159-176.

Triandis, H. C. (1980). Values, attitudes, and interpersonal behavior. In M. M. Page (Ed.), 1979 Nebraska symposium on motivation: Beliefs, attitudes, and values (pp. 195-259). Lincoln, NE: University of Nebraska Press.

Wallenius, M. (2000). Personal project level of abstraction and project conflict: Relations to psychological well-being. European Journal of Personality, 14, 171-184. 
Table 1. Correlations and descriptives of Time 2 behaviour, social cognitions and goal constructs and descriptive Statistics $(\mathrm{N}=137)$

\begin{tabular}{|c|c|c|c|c|c|c|c|c|}
\hline Variables & 1 & 2 & 3 & 4 & 5 & 6 & Mean & $s d$ \\
\hline $\begin{array}{l}\text { 1. Time } 2 \text { Physical } \\
\text { Activity }\end{array}$ & -- & & & & & & 3.16 & 2.38 \\
\hline 2. Intention ${ }^{1}$ & $.38 * *$ & -- & & & & & 5.82 & 1.11 \\
\hline $\begin{array}{l}\text { 3. Perceived } \\
\text { Behavioural Control }^{1}\end{array}$ & $.35 * *$ & $.60 * *$ & -- & & & & 5.46 & 1.31 \\
\hline 4. Attitude ${ }^{1}$ & $.36 * *$ & $.70 * *$ & $.66 * *$ & -- & & & 5.95 & 0.90 \\
\hline 5. Subjective Norm ${ }^{1}$ & $.23 * *$ & $.40 * *$ & $.40 * *$ & $.45^{* *}$ & -- & & 5.46 & 1.19 \\
\hline 6. Conflict ${ }^{2}$ & -.14 & -.06 & -.16 & $-.21 *$ & $-.18 *$ & -- & 3.77 & 1.89 \\
\hline 7. Facilitation ${ }^{2}$ & $.31 * *$ & $.21^{*}$ & $.31 * *$ & $.34 * *$ & $.22 *$ & -.12 & 3.83 & 1.98 \\
\hline
\end{tabular}

$* * p<.01 ; * p<.05$

${ }^{1}$ scale $1=$ low INT/PBC/ATT/SN 7 = high INT/PBC/ATT/SN

${ }^{2}$ scale $0=$ low conflict/facilitation with physical activity, $10=$ high conflict/facilitation with physical activity 
Table 2. Hierarchical regression of Time 2 self-reported frequency of physical activity on TPB proximal predictors, intergoal facilitation, and interactions

\begin{tabular}{|c|c|c|c|c|c|}
\hline & & & & \multicolumn{2}{|c|}{$\begin{array}{c}95 \% \text { CI B } \\
\text { Coefficient }\end{array}$} \\
\hline & $\Delta R^{2}$ & $\beta$ & $B$ & Lower & Upper \\
\hline \multirow[t]{3}{*}{ Step 1} & $.166^{* *}$ & & & & \\
\hline & Perceived Behavioural Control* & .20 & .34 & .00 & .71 \\
\hline & Intention** & .26 & .56 & .14 & .97 \\
\hline \multirow[t]{4}{*}{ Step 2} & $.043^{* *}$ & & & & \\
\hline & Perceived Behavioural Control & .13 & .24 & -.12 & .60 \\
\hline & Intention* & .25 & .54 & .13 & .95 \\
\hline & Intergoal Facilitation** & .22 & .26 & .07 & .46 \\
\hline \multirow[t]{5}{*}{ Step 3} & $.227 * *$ & & & & \\
\hline & Perceived Behavioural Control & -- & .26 & -.10 & .61 \\
\hline & Intention** & -- & .62 & .20 & 1.04 \\
\hline & Intergoal Facilitation** & -- & .28 & .09 & .47 \\
\hline & $\begin{array}{l}\text { Intention X Intergoal } \\
\text { Facilitation }\end{array}$ & -- & .14 & -.01 & .29 \\
\hline
\end{tabular}

${ }^{* *} p<.01 ;{ }^{*} \mathrm{p}<.05$ 
Figure Captions

Figure 1. Bootstrapped mediation models of intergoal facilitation's effect on Time 1 intention and Time 2 behaviour 
$B=.12 *(.00)$

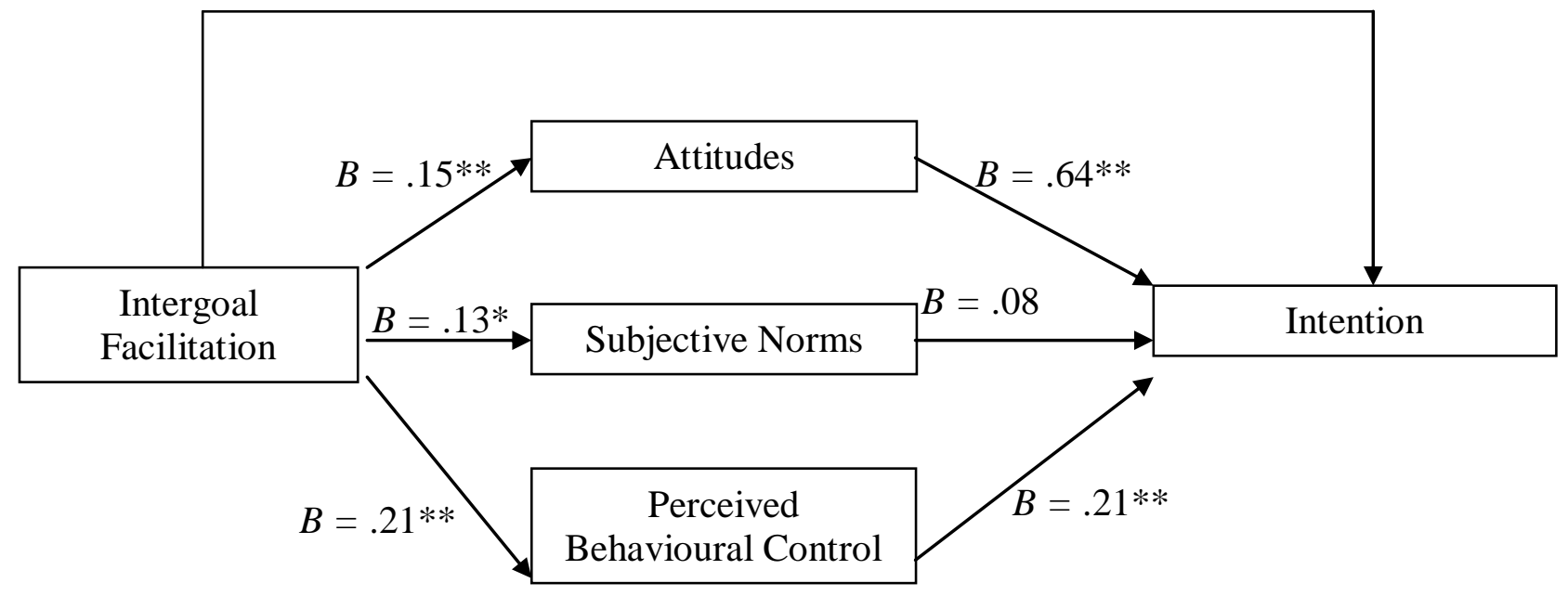

$B=.37^{* *}\left(.29^{* *}\right)$

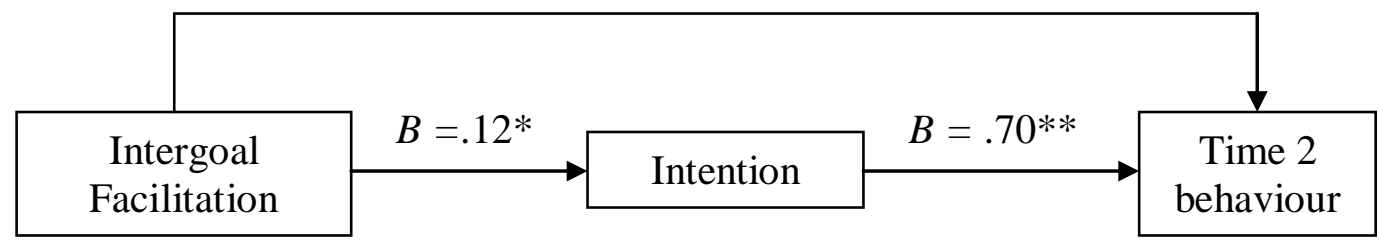

Note: $B=$ un-standardised regression coefficients. The total effect of intergoal facilitation on intention before accounting for the mediating variables is presented outside the parenthesis while the direct effect of intergoal facilitation after accounting for the mediators is within parenthesis. ${ }^{*} \mathrm{p}<.05$; ${ }^{* *} \mathrm{p}<.01$ 